\title{
CAD Training Using Interactive Computer Sessions
}

\author{
Jorge Rodriguez, James Ridge, Amy Dickinson, and Ronald Whitwam \\ Western Michigan University / Steelcase, Inc.
}

\begin{abstract}
$\underline{\text { Abstract }}$
This project addresses the need to train CAD users on proper modeling methodology. New CAD software empowers designers with the flexibility of parametric or variational design. These feature-based parametric modeling packages allow modification of a solid model by changing its dimensional parameters; however, incorrect modeling methodology may cause failure in the design stage. Failures occur when modified dimensions cause a conflict within the geometry of the model. An option being used is to train designers on capturing the Design Intent of a system through proven techniques in the modeling process. This training is based on interactive computer sessions that guide the designer and allow him/her to explore what-if scenarios. This project sought to identify proven techniques in the modeling process for capturing the Design Intent of mechanical systems. The familiar components of a bicycle provided a basis for exploration. Pro/Enginner ${ }^{\mathrm{TM}}$ software was used in this study. Nine lessons were created and tested by professionals. Beta testing was conducted at Steelcase-Chair Division with positive feedback from novice and advanced CAD users.
\end{abstract}

$\underline{\text { Introduction }}$

Within the past two decades, the advent of computer technology has enabled hundreds of disciplines to expand their horizons. Computer Aided Design (CAD) has progressed to a level that permits solid modeling of systems as complex as the human knee ${ }^{(2)}$. Design tools such as parametric modeling, used by Parametric Technology Corporation (PTC)'s Pro/Engineer integrated manufacturing software, enable engineering teams to rapidly create and analyze models. Parametrics provides the ability to modify an existing model by changing its dimensions, and represents the key to feature driven representation and design. However, the flexibility permitted by parametrics presents an array of new problematic issues, such as conflicting geometry or unattached features.

The concept of Design Intent represents a primary issue of parametric modeling. Design Intent addresses the need for preliminary study before adding features because geometric relationships within the model must be preserved ${ }^{(5)}$. Critical problems may arise if an engineer creates a solid model without taking into account the importance of Design Intent. Without proper forethought, construction of a solid model can reach a critical stage where parametric manipulation is no longer possible. When this occurs, subsequent changes may cause an internal failure of the associated geometry. Prevention of failures, and maximum design flexibility, reflect the goals of Capturing Design Intent. PTC's Pro/Engineer (Pro/E) is probably the most efficient integrated software package today which is capable of generating solid models ${ }^{(7)}$. Design Intent is a concept which requires the engineer to study a part before attempting to create the model on Pro/E. The 
engineer must decide how to relate each feature of the model to the model itself, instead of simply assigning a dimension to that feature. If improperly designed, models may become inoperable when engineers attempt to modify them. Since a single solid model can be modified to create other related product designs, it is important to the engineer and the company that models be created using proper Design Intent techniques ${ }^{(1)}$.

Proper modeling techniques require preliminary planning, as well as proper use of CAD system specific functionality, to create robust models. By using certain techniques, such as relations, and focusing on Design Intent, the probability of robust models is greatly increased and wasted time and wages is virtually eliminated ${ }^{(3)}$. Often in industry, design alterations are made which may require changing the solid model dimensions. A model, created without consideration of Design Intent, may need hours of labor to implement changes, which typically should require little time and effort. Consequently, the additional time spent correcting these problems and rebuilding the models results in thousands of wasted company dollars. Overall, the basic need for using and understanding the concept of Design Intent is to eliminate the inefficiencies of recreating models and increase the company's productivity ${ }^{(8)}$.

Ideally, in order to be effective, the concept of Design Intent must first be understood in the basic learning of modeling techniques. This study describes modeling methods for building Design Intent into a Pro/E solid model. Through the self-paced tutorials in this study, this goal has been accomplished. Using the familiar components of a bicycle to create a bridge between theory and practice, the tutorial package generates motivation towards completion of the lessons. Divided into three progressive levels, the project composed a framework of basic to advanced application using the modeling methods presented. Beginning with creating basic Datum Planes, and ending with creating an assembly of the developed parts onto a skeleton, these tutorials demonstrate the need for proper design preparation when using parametrics.

\section{$\underline{\text { Methodology }}$}

The comprehensive tutorial package developed in this study has the goal of enabling designers to learn modeling techniques and apply them properly to capture Design Intent; thus producing stable models, saving time, money, and allowing a company to get the products to its customers in an efficient and timely manner. The specific steps taken, that basically reflect the objectives of this study, are as follow:

- Identifying Techniques. Based on the authors' experience and familiarity with the software, a list of features/techniques offering achievement of the project objectives was defined. These ideas generated a set of tutorial topics, which were methodically reduced to twenty-two techniques. Although a variety of special techniques found direct use within the tutorials, each of the nine tutorials highlighted only a chosen subset while illustrate Design Intent.

- Defining Components. Concurrent with the selection of techniques, the team began to examine the components of a bicycle. The bicycle components provided the team with extensive resources, and offered a familiar basis for tutorial subject matter. The Complete Guide to Bicycle Maintenance ${ }^{(9)}$, provided examples of disassembled bicycle components.

- Relating Components to Techniques. The process of matching components to potential techniques required a culling of parts based on related subject matter. The vast complexity of the selected parts required the team to reject some components in favor of those components, 
which accommodated the selected techniques. Along with individual components, two assemblies were identified for inclusion. The chosen systems presented examples for the application of skeleton assemblies ${ }^{(3)}$.

- Construction of Models. After matching the part to the technique, the model construction could proceed. Prototype models provided a means of organizing the lesson model sequence. During the prototype creation, various methods revealed the best approach to pursue the final model creation. The team failed these models purposely to gain insight about features and test the Design Intent solutions. This vital step enabled better understanding of the Design Intent issues and occasionally produced some new techniques.

- Creating Lessons. In addition to the model construction needs met by prototyping, the initially constructed models needed to conform to the lesson goals and objectives. Manipulation of features, defining Design Intent "on the fly", and alternate methodology, combined to increase the importance of the initial models. Projected breakpoints provided the basis for the final model creation. Breakpoints existed as directives added to the trail file.

- Editing of Trail Files. The most critical step, editing the trail files, created the tutorial session. Within this process, the team transformed a raw trail file into an interactive computer session. Edited trail files acquired the status of training file ${ }^{(4)}$, after the insertion of special commands called directives. Adding directives to the trail file required careful manipulation of the trail file text to avoid corruption of the sequential data. This avoidance did not always take place.

- Design Tutorial Handout. The design of the tutorial handout involved a part drawing created from the successful trail file run. Balloon details identified the features included in the part as specific techniques for Capturing Design Intent. In addition to the part drawing, the handout identified the specific techniques and any special considerations of the tutorial.

- Beta Testing. The final section of each tutorial handout consisted of a survey form. During this phase, Steelcase' Pro/E users evaluated the training files during their spare time. The Steelcase Seating Group personnel graciously contributed as much time as they could afford.

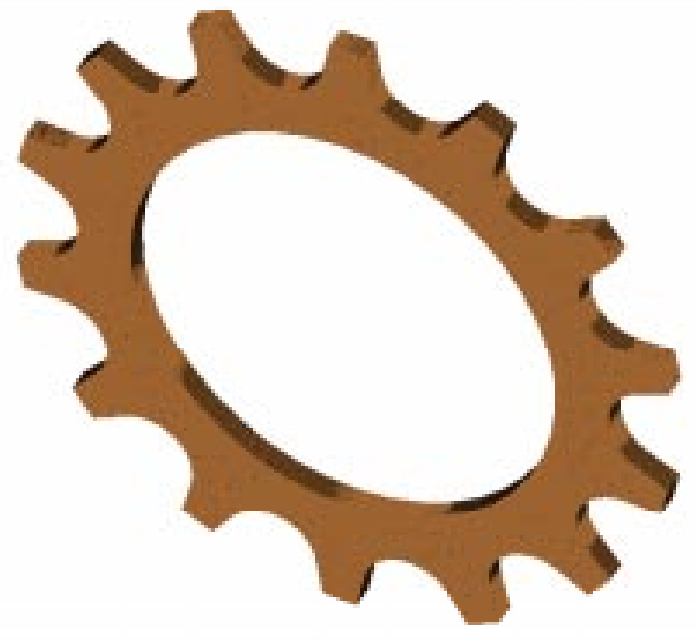

Figure 1. Sprocket created during Lesson 5. Use of Relationships and Pro/ Program techniques.

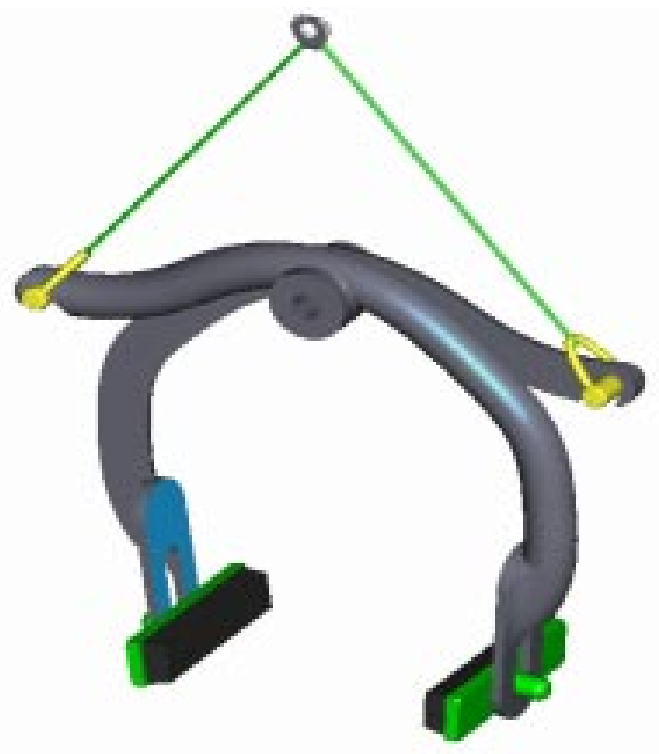

Figure 2. Brake Assembly created during Lesson 8. Use of Skeleton and Assembly techniques. 


\section{$\underline{\text { Results and Evaluations }}$}

The project resulted in nine tutorial lessons. Within those nine lessons, twenty-two techniques for Capturing Design Intent offered an in depth methodology for this parametric - feature based modeling package. Table 1 provides a breakdown of the techniques resulting from the combined team effort. The team determined early in the project that individual techniques could not stand alone as lessons. Part of that decision was based on the need to create complete bicycle parts. The bicycle components selected for each of the actual tutorial lessons are as follows:

$\begin{array}{lll}\text { Lesson } 1 \text { - Frame } & \text { Lesson 2 - Handlebars } & \text { Lesson 3 - Back Bracket } \\ \text { Lesson } 4 \text { - Back Fork } & \text { Lesson 5 - Sprocket } & \text { Lesson 6 - Caliper } \\ \text { Lesson } 7 \text { - Seat } & \text { Lesson } 8 \text { - Brake Assembly } & \end{array}$

Lesson 0 is a basic introduction to the features in Pro/E software. Figures 1 and 2 show some of the final models created with the lessons. Figure 3 shows a typical text block used to guide the user during the interactive tutorial.

Beta Test. After completing the interactive tutorial sessions, each lesson was tested by a team of professional Pro/E users. The Beta testers have all worked with Pro/Engineer for an average of approximately four years. Each Beta tester was then asked to complete a survey which asked a series of questions about the complexity, length, effectiveness, and interest level of each of the tutorial lessons. The results were quite positive in that every Beta tester gave us average to high scores on each of the lessons (Figure 4). Most importantly, we felt that the interest level was the most significant question in the survey. Typically, from personal experience, we felt that standard tutorials may become monotonous and trivial for users to learn from. By developing interactive tutorial lessons, we have achieved an exciting alternative to those standard tutorials. Through our lessons, the student had the opportunity to actually see how the parts were being produced, understand the reasons why they were being created in that particular fashion, and be familiar with the parts being created since we were using basic bicycle components.

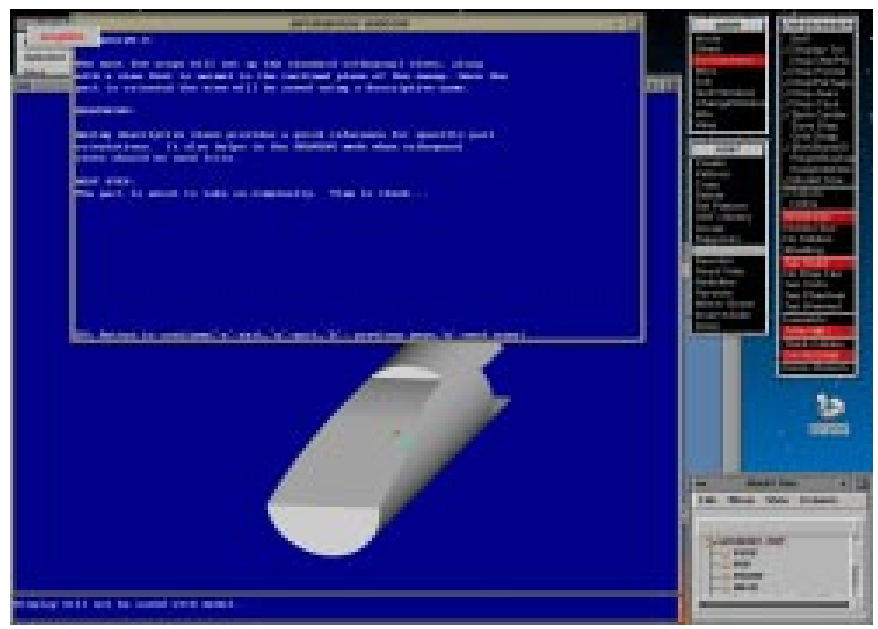

Figure 3. Sample of Interactive Session.

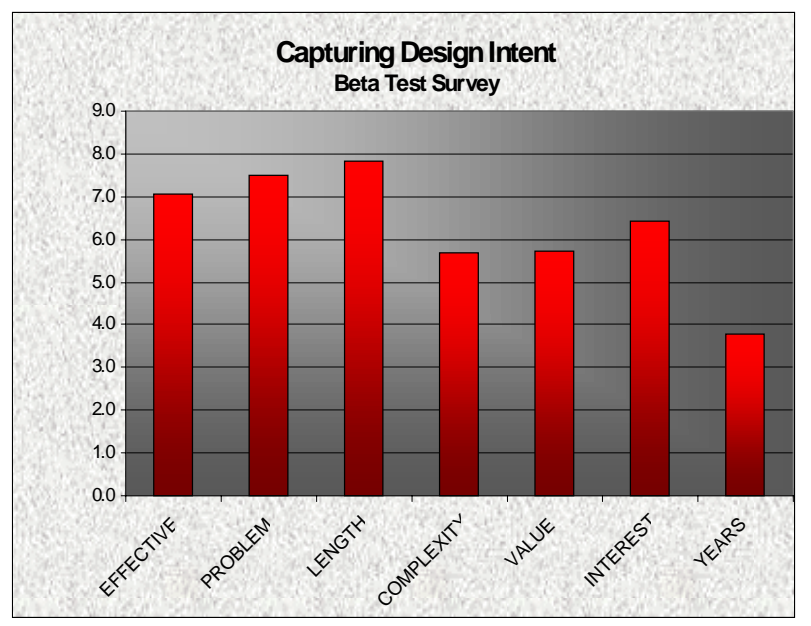

Figure 4. Beta Test Results. 
Overcoming Version Upgrades. One of the major problems faced was the version upgrades with the software. These tutorials were started in Version 17 (WMU and Steelcase had it), but WMU moved to Version 18 at the beginning of the new academic semester while Steelcase delayed the upgrade by 3 months. To accommodate Beta testing, the team maintained the training files in Version 17 until Steelcase upgraded to the newer version. Many of the files failed with "out of sequence" errors after the version upgrade. No immediate complete solutions emerged and they were tested in version 17 . Currently all tutorials have been upgraded.

\begin{tabular}{|c|c|c|c|c|c|c|c|c|c|}
\hline TABLE 1. & & \multicolumn{8}{|c|}{ Lesson Number } \\
\hline Technique & 0 & 1 & 2 & 3 & 4 & 5 & 6 & 7 & 8 \\
\hline Reordering Features & $\mathrm{X}$ & & & & & & & & \\
\hline Using Swept Cuts & $\mathrm{X}$ & & & & & & & & \\
\hline Datum Planes on the Fly & & $\mathrm{X}$ & & & & $\mathrm{X}$ & & & \\
\hline Datum Planes Normal to a Flexible Axis & & $\mathrm{X}$ & & & & & & & \\
\hline Extruding Up to A Surface & & $\mathrm{X}$ & & & & & & & \\
\hline Positioning a Sweep Section & & & $\mathrm{X}$ & & $\mathrm{X}$ & & & & \\
\hline Datum Curve Sweep Trajectories & & & $\mathrm{X}$ & & & & $\mathrm{X}$ & & \\
\hline Mirrored Geometry & & & $\mathrm{X}$ & & & & & & \\
\hline Independent Radial Copying & & & & $\mathrm{X}$ & & & & & \\
\hline Placing Saved Sections & & & & $\mathrm{X}$ & $X$ & & & & \\
\hline Moving Point Reference & & & & $\mathrm{X}$ & & & & & \\
\hline Multiple Point Plane Definition & & & & & $X$ & & & & \\
\hline Anchoring Curves to Points & & & & & $\mathrm{X}$ & & & & $\mathrm{X}$ \\
\hline General Patterns & & & & & & $\mathrm{X}$ & & & \\
\hline Complex Relations & & & & & & $\mathrm{X}$ & & & \\
\hline Pro-Program Feature Control & & & & & & $\mathrm{X}$ & & & $\mathrm{X}$ \\
\hline Spline Curves as Sweep Trajectories & & & & & & & $\mathrm{X}$ & & \\
\hline Replace Surface Feature & & & & & & & $\mathrm{X}$ & & \\
\hline Controlling Shape with Multiple Conic Curves & & & & & & & & $\mathrm{X}$ & \\
\hline Conic Rounds & & & & & & & & $\mathrm{X}$ & \\
\hline Skeleton Parts & & & & & & & & & $\mathrm{X}$ \\
\hline Assembly Methods for Skeleton Performance & & & & & & & & & $\mathrm{X}$ \\
\hline
\end{tabular}

\section{$\underline{\text { Conclusions }}$}

This study has proven that interactive-session tutorials are a valid option for effective learning of CAD techniques. This study used a new style of tutorials, which will aid present and future designers in learning the concept of Design Intent. Unlike traditional tutorials, which basically teach the student just how to create solid models, the interactive tutorials design goes further in 
depth by not only teaching the user how something was created, but also why it was created in that particular manner.

The theory of Design Intent was integrated into the creation of several 3-D solid models of basic bicycle. It can be concluded that these tutorial sessions successfully conveyed the problem of Design Intent. As previously stated, the completed Beta testers survey provided us with insight as to how well our tutorials demonstrated that a Design Intent issue existed and needed to be addressed. However, it was also proved that these trail files, which are the basis for the interactive lessons, are not robust. It was discovered that the trail files are not easily integrated between different versions of the CAD package used. Therefore, in order to continue using these trail files in the future, they will require continuous maintenance to be used with more advanced versions of Pro/E.

Future studies in the area of capturing the Design Intent for solid models will include more interaction between the user and the lesson. Currently, the tutorial lessons integrate text block windows, into the lesson, which explain the reasoning behind the creation of each feature in a part. Ideally, proceeding lessons should be created in a way so that the user has more options of making menu picks and making choices in each step that occurs

\section{$\underline{\text { References }}$}

1. Bigelow, D. (1996). Thinking Pro/Engineer. Santa Fe: Onword Press.

2. Columbia University. (1997, March 16). Solid Modeling of Physiological Geometries. [WWW]

3. McLellan, T., \& Karam, F. (1996). Pro/Engineer, Tips and Techniques. Santa Fe: Onword Press.

4. Pro/Engineer Administration Guide, Version 17 (1996). Chapter Five Training Files. Parametric Technology Corporation, Waltham, MA

5. Pro/Engineer Fundamentals, Release 17 (1996). Capturing Design Intent, P 2-8,

6. Mechanical Design Automation For Design-Through-Manufacturing, 1994, Parametric Technology Corporation, Waltham, MA

7. Teresco, J. (1993). Parametric Technology Corp. changing the way products are designed, Cleveland, Penton Publishing. [Brochure].

8. Utz, J., \& Cox, R. (1995). Inside Pro/Engineer. Santa Fe: Onword Press.

9. Wolf, R. et al (1990). Complete guide to bicycle maintenance and repair. Emmaus PA, Rodale Press.

$\underline{\text { Authors }}$

JORGE RODRIGUEZ. Assistant Professor at Western Michigan University. Ph.D. from University of WisconsinMadison, MBA from Rutgers University, BS from ITESM-Monterrey, Mexico. Areas of expertise are CAD/CAM/ CAE, Optimization, Finite Element Method and Biomechanics. Experience in steel-making industry and IS.

JAMES RIDGE. Computer Graphics and Design Program at Western Michigan University. President Scholar at WMU. Senior Chief Aviation Electronics Technician while at the U. S. Navy. Currently Design Engineer at Steelcase North America, Inc. - Seating Product Division.

AMY DICKINSON. Computer Graphics and Design Program at Western Michigan University. Teaching Assistant for Computer Graphics courses at WMU. Member of Tau, Alpha, Pi and SWE. Currently Design Engineer at Prince Corporation - Johnsons Controls, Inc.

RONALD WHITWAM. Manager, Seating Product Development for Steelcase North America, Inc. BS in Mechanical Engineering from Ferris State University (Big Rapids, MI). Extensive experience in furniture industry. 